\title{
Effects of Excitatory Amino Acid Antagonists on the Phasic Depolarizing Events That Occur in Lumbar Motoneurons during REM Periods of Active Sleep
}

\author{
Peter J. Soja, ${ }^{a}$ Faustino López-Rodríguez, Francisco R. Morales, and Michael H. Chase \\ Departments of Physiology, Anatomy, and Cell Biology and the Brain Research Institute, UCLA School of Medicine, \\ Los Angeles, California 90024
}

\begin{abstract}
The membrane potential of lumbar motoneurons is dominated during the tonic periods of active sleep by glycinemediated inhibitory postsynaptic potentials (IPSPs). During the phasic rapid eye movement (REM) periods of active sleep there are also IPSPs but, in addition, the membrane potential exhibits depolarizing shifts and action potentials that occur in conjunction with the phasic activation of the somatic musculature. The present study was designed to provide evidence that an excitatory amino acid (EAA) neurotransmitter is responsible for these patterns of motoneuronal activation. It was found that juxtacellular microiontophoretic applications of kynurenic acid, a non-NMDA antagonist of EAA neurotransmission, blocked the depolarizing potentials of motoneurons that arise during the REM periods of active sleep. In contrast, the selective NMDA receptor antagonist APV did not block these depolarizations. The conclusion is drawn that the myoclonic twitches and jerks that characterize the REM periods of active sleep are dependent upon the excitation of motoneurons that occurs as a result of EAAs acting at non-NMDA receptors.
\end{abstract}

[Key words: 2-amino-5-phosphonovalerate, excitatory postsynaptic potential, excitatory amino acid, kynurenic acid, motoneuron, REM sleep, spinal cord]

Motor processes during active sleep are characterized by muscle atonia and the depression of somatic reflexes (Jouvet et al., 1959; Chase and Babb, 1973; for review, see Chase, 1974). The reduction in somatomotor activity during the tonic periods of active sleep that lack rapid eye movements (REMs) is produced principally by the bombardment, upon motoneurons, of glycinergic inhibitory postsynaptic potentials (IPSPs) (Morales and Chase, 1982; Morales et al., 1985; Chase et al., 1989; Soja et al., 1991). During the REM periods of active sleep there is an additional reduction in reflex amplitude and an increase in the frequency of occurrence and amplitude of motoneuron IPSPs (Gassel et al., 1964b; Chase, 1970; Chase and Morales, 1983). The IPSPs that bombard motoneurons during these phasic REM periods are also mediated by glycine or a glycine-like neuro-

\footnotetext{
Received Oct. 3, 1994; revised Dec. 13. 1994; accepted Dec 16, 1994

This work was supported by USPHS Grant NS 23426 . We thank Dr. W. Vota for developing the computer software employed in this study.

Correspondence should be addressed to Dr. M. H. Chase, Department of Physiology, Center for the Health Sciences, UCLA School of Medicine, Los Angeles, CA 90024.

Present address: Faculty of Pharmaceutical Sciences. The University of British Columbia, 2146 East Mall, Vancouver, BC Canada V6T 1Z3.

Copyright (1995 Society for Neuroscience 0270-6474/95/154068-09\$05.00/0
}

transmitter (López-Rodríguez et al., 1991), which has led to the suggestion that activity of the same motor inhibitory system that is engaged during the tonic periods of active sleep is further enhanced during periods of REMs (López-Rodriguez et al., 1991). Paradoxically, there are also muscle twitches and jerks that occur during the REM periods of active sleep. The basis for the myoclonic activity that occurs during these periods has been shown, by recording intracellularly from lumbar motoneurons in unanesthetized, undrugged cats, to be based upon repetitive depolarizing shifts in membrane potential, which often lead to bursts of action potentials. These excitatory events arise against a concurrent background of membrane hyperpolarization and a flurry of IPSPs (Chase and Morales, 1982, 1983).

Compared with the data that have accumulated regarding the tonic and phasic inhibitory events that occur during the nonREM and REM periods of active sleep, relatively little is known about the mechanisms that are responsible for the production of the depolarizing and action potentials that are present during the REM periods of active sleep. Previous studies have shown that lesions of the dorsolateral funiculi abolish myoclonic jerks below the level of the lesion (Gassel et al., 1964a,b). It is therefore likely that motoneuron activation during these periods is due to postsynaptic potentials that reflect the activity of supraspinal structures, rather than being the result of disinhibition.

Excitatory amino acids (EAAs) are likely candidates for the production of these potentials for several reasons. First, aspartate and glutamate have been found in the spinal cord (Graham et al., 1967; Johnson and Aprison, 1971) and their excitatory action on lumbar motoneurons has been documented (Curtis et al., 1960; Engberg et al., 1979; Zieglgansberger and Champagnat, 1979; sce revicws by Puil, 1981; Mayer and Westbrook, 1987; Collingridge and Lester, 1989; Evans, 1989; Headley and Grillner, 1990). Second. EAA levels decrease following spinal cord lesions, suggesting that they are released from terminals of descending tracts that project to spinal cord neurons (Rizzoli, 1968; Fagg and Foster, 1983; Young et al., 1983); earlier studies have indicated that activity in these descending pathways is responsible for muscle twitches during the REM periods of active sleep (Gassel et al., 1964a,b). In addition, stimulation of peripheral nerves has been shown to produce excitatory potentials in lumbar motoneurons that are blocked by EAA antagonists (Engberg et al., 1993; Walmsley and Bolton, 1994). These data support the conclusion that amino acids, such as glutamate, may serve as a candidate neurotransmitter mediating "fast" excitatory synaptic transmission in the spinal cord.

The present investigation was designed to determine whether 
lumbar motoneuron membrane-depolarizing events during the REM periods of active sleep are mediated by an EAA neurotransmitter. Accordingly, kynurenic acid, which is a broad-pectrum EAA antagonist acting at NMDA receptors (AMPA) and kainate receptors (Perkins and Stone, 1982; Ganong et al., 1983), and the selective NMDA antagonist 2-amino-5-phosphonovalerate (APV) (Davis et al., 1981; Perkins et al., 1981) were ejected juxtacellularly while recording intracellularly from lumbar motoneurons during sleep and wakefulness.

\section{Materials and Methods}

Experiments were performed on five chronically prepared cats that were undrugged, unanesthetized, and normally respiring. Details of the procedures for recording intracellularly from spinal cord motoneurons and for monitoring electroencephalographic (EEG), ocular (EOG), pontogeniculo-occipital (PGO), and electromyographic (EMG) activity to differentiate states of sleep and wakefulness have been previously reported (Morales et al., 1981). Surgical procedures were carried out while the animals were anesthetized with sodium pentobarbital $(40 \mathrm{mg} / \mathrm{kg})$ and placed in a stereotaxic instrument (Morales et al,, 1981).

The skin was reflected from the calvarium and screw electrodes were inserted (1) in the frontal bone over the sigmoid gyri to monitor EEG activity and (2) in the orbital portion of the frontal bone to record EOG activity (Ursin and Sterman, 1981). A recording bipolar strut electrode was placed in the lateral geniculate body (A6, L10.5, H3.5) to monitor PGO activity. Insulated wires from all electrodes were subsequently soldered to a 20-pin connector that was then cemented to the calvarium with acrylic resin.

Preparation of the spinal cord to permit chronic intracellular recording from lumbar motoneurons was accomplished as follows. After exposure of the vertebral column, miniature stainless steel screws were implanted bilaterally in each of the articular processes of the vertebrae between L 3 and S1 to immobilize the articulations. Specially constructed hard plastic (Delrin) clamps were placed around L3, L4, and L6 to stabilize the vertebral column (Morales et al., 1981). The above assembly. except for the area over L5, was bonded together with dental cement. A recording access chamber was fashioned in the acrylic overlying the dorsal lamina of the L5 vertebra. Twenty-four hours prior to the beginning of the recording sessions and under gaseous halothane anesthesia, a small hole $(1.5-2 \mathrm{~mm}$ diameter) was placed in the L5 dorsal lamina to enable a micropipette to be lowered into the underlying L6-L7 motoneuron pools. Recording sessions lasted for $5-6 \mathrm{hr} / \mathrm{d}$ for $2-3$ consecutive days. The hole was filled with antibiotic cream and the recording chamber sealed with sterile bone wax between recording sessions. Molded silicone electrodes were permanently implanted around the sciatic nerve for antidromic stimulation of lumbar motoneurons.

Intracellular recordings were obtained from "control" motoneurons utilizing beveled single-barrel micropipettes filled with $2 \mathrm{M} \mathrm{K}^{+}$-citrate. Subsequently, the single-barrel electrode was replaced with a composite "piggyback" glass micropipette that was used to record intracellularly and to microiontophoretically eject drugs juxtacellularly (Soja et al., 1987, 1991; Chasc et al., 1989). Bricfly, composite electrodes consisted of a center barrel filled with $2 \mathrm{M}$ potassium citrate (5-15 $\mathrm{M} \Omega$ resistance) and a four-barrel glass micropipette assembly. The tips of the latter assembly were broken under a microscope to a total diameter of 6-12 $\mu \mathrm{m}$ and affixed with cyanoacrylate cement to the intracellular recording glass micropipette. The tip of the recording micropipette extended beyond the tips of the drug ejection micropipettes by $75-100 \mu \mathrm{m}$. The three micropipettes that were used for drug ejection were filled kynurenic acid $(150 \mathrm{~mm}, \mathrm{pH}$ 8) or 2-amino-5-phosphonovalerate (APV; 200 $\mathrm{mM}, \mathrm{pH}$ 8). Multiple barrels of the same EAA antagonist were employed to ensure that an adequate drug release occurred while recording intracellularly during states of sleep and wakefulness. In selected studies, one of the barrels was filled with NMDA $(200 \mathrm{~mm}, \mathrm{pH} 8)$ and the other two with APV (200 mM. $\mathrm{pH} 8$ ). The remaining barrel of the drug ejection assembly was filled with $2 \mathrm{M} \mathrm{NaCl}$ for automatic current balancing. Retaining currents $(+5 \mathrm{nA})$ were applied to the drug barrels in situ to minimize drug leakage.

Drugs were released from multiple barrels using anionic currents delivered from a current generator (Neurophore BH2, Medical Systems Inc.). Summed constant currents of $519 \pm 49 \mathrm{nA}$ were applied for kynurenic acid ( \pm SEM here and below; range, 250-900 nA) and 600 $\pm 77 \mathrm{nA}$ for APV (range, $450-900 \mathrm{nA}$ ). NMDA was applied over 30

\section{A. Control}

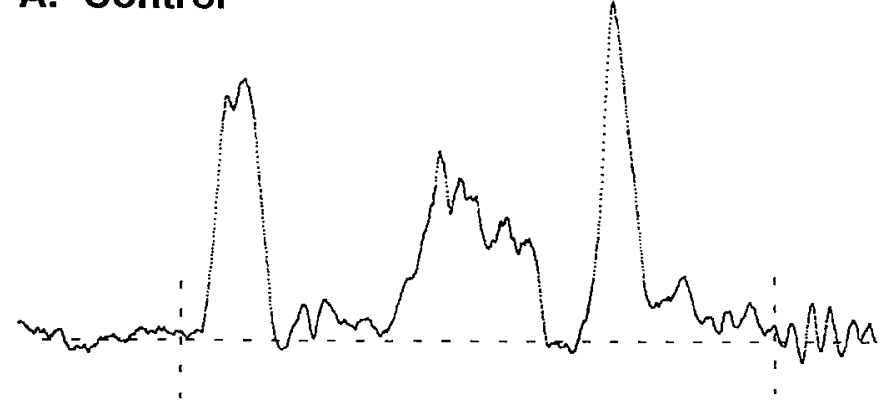

\section{B. Kynurenic Acid}

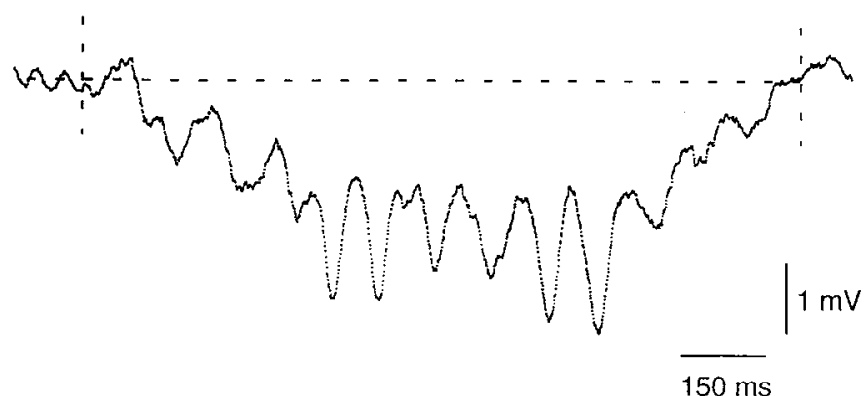

Figure 1. Membrane potential during REM periods of active sleep of a control lumbar motoneuron $(A)$ and a motoneuron exposed to kynurenic acid $(B)$. Horizontal dashed lines mark the baseline of the membrane potential; vertical dashed lines indicate the onset and termination of the changes in membrane potential during the corresponding REM periods; analyses of the areas encompassed by changes from the baseline in membrane potential were performed between these vertical lines (see text). Positive areas predominated in the control motoneuron and negative areas were most prevalent in the motoneuron exposed by kynurenic acid.

sec periods using ejection currents of $250-450 \mathrm{nA}$ (see below). Atter cell impalement and stabilization of recording conditions, the ejection of kynurenic acid either was maintained until the end of the intracellular recording or was terminated before the end of the recording to determine whether there was a recovery from the drug's effect. In motoneurons exposed to APV, EPSPs evoked by sciatic nerve stimulation or motoneuronal depolarizations evoked by regular applications of NMDA were examined before and during the ejection of APV. The ability of microiontophoretic applications of APV to suppress the activities induced during the preceding procedures was used to verify that the drug was being released. NMDA was applied in cycles of $30 \mathrm{sec}$ on-30 sec off, with and without simultaneous continuous ejections of APV. The mean duration of drug application before the onset of active sleep was $2 \pm 0.5 \mathrm{~min}$ in the casc of kynurenic acid and $10 \pm 5 \mathrm{~min}$ for APV. During recording sessions involving the aforementioned microiontophoretic procedures, the cats readily went to sleep and did not exhibit any behaviors that would indicate that they were uncomfortable or stressed

To obtain a quantitative evaluation of the effect of kynurenic acid and APV on the depolarizing events during the REM periods of active sleep, the following procedures were performed (Fig. 1). First, the motoneuron membrane potential data were passed through a $3 \mathrm{kHz}$ lowpass filter. A Macintosh Quadra computer was programmed to digitize the filtered membrane potential activity ( $50 \mu \mathrm{sec}$ bin width). Then, two points that marked the beginning and end of the phasic changes in membrane potential that corresponded to the time defined as a rapid eye movement episode were determined. Analyses were confined to the 
period between these two data points. The areas encompassed by deviations above baseline in the membrane potential between these data points were considered positive; negatives areas were those below baseline. In addition, area:duration ratios (i.e., the area divided by the duration of the selected period) were computed. This normalization procedure was quite useful since it compensated for the variable durations of individual phasic REM episodes during active sleep. The preceding normalization procedures were performed to provide an indication of the relative strength of the depolarizing and hyperpolarizing potentials. For example, in the case of a blockade of depolarizing shifts (Fig. $1 B$ ), negative area measurement values were computed when hyperpolarizing potentials predominated. Statistical analyses were performed using the unpaired Student's $t$ test; $\alpha$ was set at 0.05 .

\section{Results}

Forty-nine motoneurons were recorded during sleep and wakefulness. Twenty-seven motoneurons were recorded during control conditions, 16 during exposure to kynurenic acid, and 6 during the application of APV. Only motoncurons with action $\mathrm{f}$ tentials greater than $55 \mathrm{mV}$ and with stable membrane potentials were utilized in the present study. The average time of intracellular recording was of $24 \pm 3 \mathrm{~min}$.

Visual inspection of the records indicated that both depolarizing and hyperpolarizing shifts in membrane potential were present during the REM periods of active sleep in lumbar motoneurons; however, different patterns of depolarization and hyperpolarization occurred for each motoneuron, as previously described (Chase and Morales, 1983). Figures $1 A$ and $2 A$ consist of examples of changes in membrane potential during REM periods in two different control motoneurons. As shown in Figure $1 A$ and the left portion of Figure $2 A$, membrane potential activity was dominated by large-amplitude depolarizing shifts that had a relatively rapid onset. These depolarizing shifts occasionally overrode the ongoing barrage of IPSPS (Morales and Chase, 1982), so that the threshold for spike discharge was reached, as portrayed in the right side of Figure $2 A$.

In contrast, the membrane potential activity of lumbar motoneurons exposed to kynurenic acid was dominated by phasic, discrete, large-amplitude, repetitive hyperpolarizing shifts in membrane potential. As we have previously reported, these hyperpolarizing shifts were blocked by microiontophoretically ejected strychnine, an antagonist of glycine (Curtis et al., 1960), indicating that they are probably mediated by glycine (LópezRodríguez et al., 1991). A common feature of motoneurons exposed to protracted ejections of kynurenic acid was that only infrequently were depolarizing shifts in membrane potential observed. However, when depolarizing shifts were still present during or after the microiontophoretic ejection of kynurenic acid, they were always smaller in amplitude than those recorded prior to the drug's release or in "control" motoneurons recorded with a single-barrel micropipette. In Figures $1 B$ and $2 B$ are presented two examples in which there are characteristically fewer smalleramplitude depolarizing shifts in membrane potential activity. A key feature in these records is the marked hyperpolarizing shifts; in point of fact, when the membrane potential during these two particular REM periods was expanded, synaptic activity was found to consist predominantly of miniature IPSPs similar to those reported previously (Morales et al, 1985).

In two motoneurons, REM-related changes were examined during exposure to kynurenic acid as well as after the cessation of drug injection. One of these motoneurons was recorded during three consecutive episodes of active sleep; in the first two active sleep episodes, the motoneuron was exposed to the ejection of kynurenic acid; the third active sleep episode occurred 5

\section{A. Control}

$E O G$

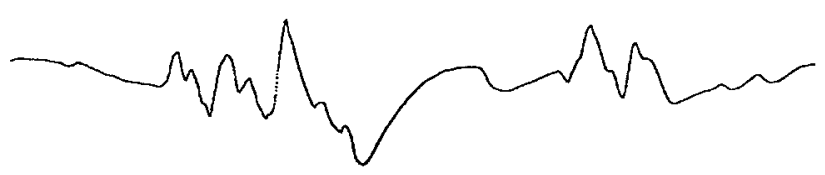

Membrane Potential

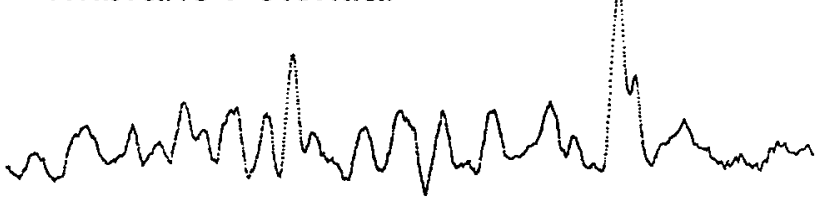

\section{B. Kynurenic Acid}
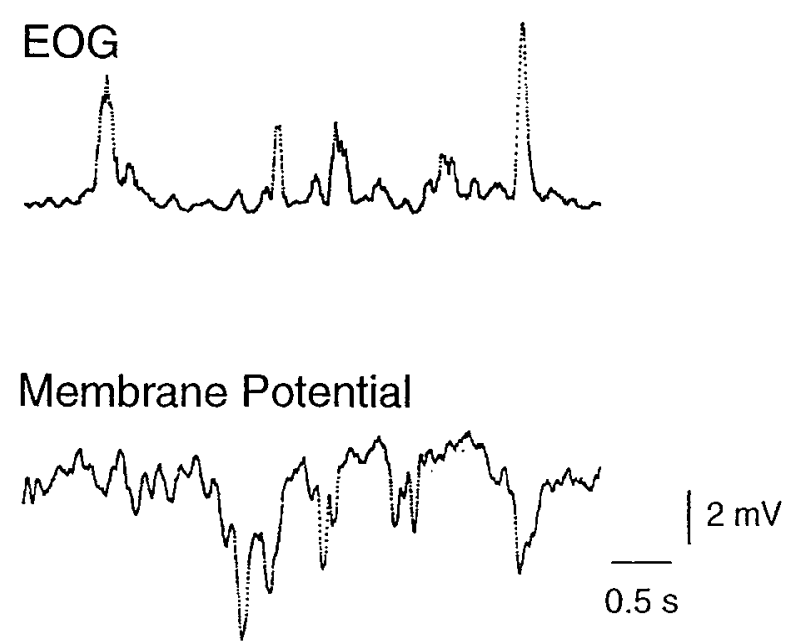

Figure 2. Membrane potential activity during REM periods of active sleep of a control motoneuron $(A)$ and a motoneuron exposed to kynurenic acid $(B)$. Kynurenic acid $(-600 \mathrm{nA})$ was ejected during quiet slecp for $5 \mathrm{~min}$ prior to active slecp and maintained throughout the duration of the active sleep episode. The membrane potential of the control motoneuron was characterized by the appearance of depolarizing shifts. However, kynurenic acid ejection blocked these depolarizing events and marked hyperpolarizing shifts were unmasked.

min after drug ejection was terminated. In the other motoneuron, the ejection of kynurenic acid was terminated before the end of the episode of active sleep; consequently, data were obtained during and after the exposure of kynurenic acid during a single period of active sleep.

REM-related phasic depolarizing potentials were diminished while kynurenic acid was being ejected; however, they reappeared approximately $30 \mathrm{sec}$ after the cessation of the ejection current. Figure 3 presents an intracellular recording of the membrane potential of a neuron that was recorded during three con- 


\section{A. Membrane Potential During Kynurenic Acid Ejection}

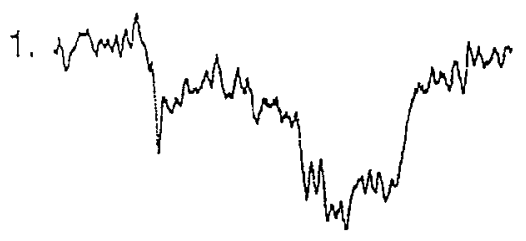

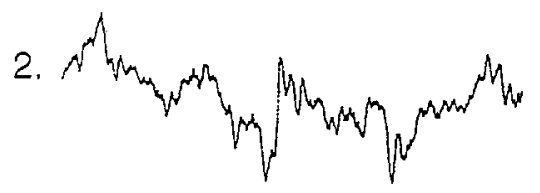

\section{B. Membrane Potential After Kynurenic Acid Ejection}
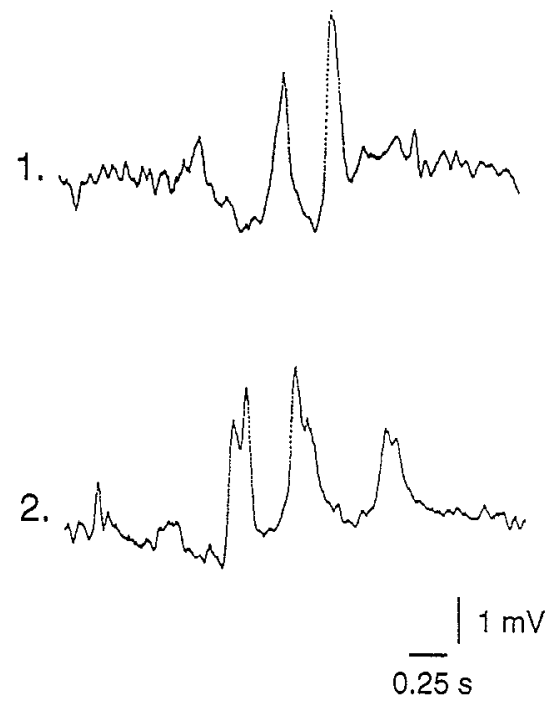

Figure 3. Periods of membrane potential activity presented in $A$ recorded during an initial active sleep period in which the motoneuron was exposed to kynurenic acid $(-750 \mathrm{nA}, 4 \mathrm{~min})$; hyperpolarizing shifts dominated the recording. In $B$ are periods of membrane potential recorded during a third active sleep episode; 5 min after the cessation of drug ejection, depolarizing shifts in membrane potential activity became strikingly evident. secutive active sleep episodes. During the exposure to kynurenic acid (Fig. 3A), the membrane potential consisted mainly of phasic inhibitory postsynaptic potentials. Depolarizing potentials were not observed. In the active sleep episode that occurred after the cessation of drug ejection, large-amplitude depolarizing potentials were evident. These depolarizing potentials had the same characteristics as those that arise in control motoneurons.

To accomplish a statistical determination of the effect of kynurenic acid on the depolarizing potentials that occurred during the REM periods of active sleep, an analysis of the area encompassed by deviations from the membrane potential baseline was performed (see Materials and Methods). This analysis was possible in a subset of motoneurons where there was a sufficiently distinct number of REM episodes that corresponded with phasic membrane potential events. The values obtained were the following: in control cells the mean positive area was $1177 \pm 169$ $\mathrm{mV} \cdot \mathrm{msec}(n=12)$ and the area:duration ratio was $0.7 \pm 0.1$ $\mathrm{mV}$. In cells exposed to kynurenic acid the mean positive area was $294 \pm 69 \mathrm{mV} \cdot \mathrm{msec}(n=10)$ and the area:duration ratio was $0.2 \pm 0.04 \mathrm{mV}$.

When the total area was considered (i.e., absolute summed values of positive and negative areas), the total areas computed for control cells were positive: the mean total area was $676 \pm$ $176 \mathrm{mV} \cdot \mathrm{msec}(n=12)$ and the area:duration ratio was $0.4 \pm$ $0.1 \mathrm{mV}$. The total areas in motoneurons exposed to kynurenic acid were negative $(-839 \pm 135 \mathrm{mV} \cdot \mathrm{msec} ;(n=10)$ as was the area:duration ratio $(-0.5 \pm 0.1 \mathrm{mV})$, which reflects a predominance of hyperpolarizing shifts. The value for total area obtained from control cells was statistically different from that obtained from motoneurons exposed to kynurenic acid $(P<$ 0.05). Microiontophoretic ejections did not alter the negative areas $(P>0.05)$, indicating that the drug was relatively specific for blocking excitatory synaptic transmission.

Kynurenic acid was also tested on short-latency EPSPs and composite polysynaptic EPSPs in two motoneurons. As shown in Figure 5A, nicroiontophoretically applied kynurenic acid was effective in partially blocking the monosynaptic EPSP evoked by low-intensity sciatic nerve stimulation. In another cell (Fig. $5 B$ ), the drug abolished the composite polysynaptic EPSP evoked by sciatic nerve stimulation; only a short-latency IPSP remained indicating again that the drug was specific for blocking excitatory synaptic transmission. Microiontophoretic ejections of kynurenic acid did not alter input resistance in four motoncurons recorded during the behavioral state of quiet sleep.

Phasic depolarizing shifts were still present when the motoneurons were exposed to APV. Visual observation of the records as well as a lack of effect of APV on the area measurements confirmed this fact. Figure 5 is an example of the depolarizing shifts during a REM period in a motoneuron exposed to APV; phasic depolarizing shifts were present and resembled those that were recorded in the control group of motoneurons. The total area measurements in motoneurons exposed to APV were 804 $\pm 387 \mathrm{mV} \cdot \mathrm{msec}$; the area:duration ratio was $0.4 \pm 0.2 \mathrm{mV}$. There was no statistical difference between these values and those obtained from control motoneurons $(P>0.05)$.

To determine if APV was producing an effect on excitatory neurotransmission, the action of APV on microiontophoretically applied NMDA and peripherally evoked composite EPSPs was examined. NMD $\Lambda$ was ejected at regular intervals $(30 \mathrm{sec}$ on, $30 \mathrm{sec}$ off) before and during the ejection of APV. Before APV application, NMDA produced a depolarization of lumbar motoneurons that lasted for a few seconds after the termination of the ejection current. As shown in Figure $6 A$, these depolarizations were accompanied by an increase (17.9\%) in the cells' input resistance. During continuous APV application, these NMDA-induced depolarizations and increase in input resistance were blocked (Fig. 6A). Aside from this specific effect of blocking NMDA-induced motoneuronal depolarizations, there was no indication that APV affected the input resistance per se in any of the cells tested during the phasic REM periods of active sleep. In addition, sciatic nerve stimulation produced mono- and polysynaptic EPSPs in lumbar motoneurons. As shown in Figure $6 B$, APV blocked a component of the composite sciatic nerveevoked EPSP. 

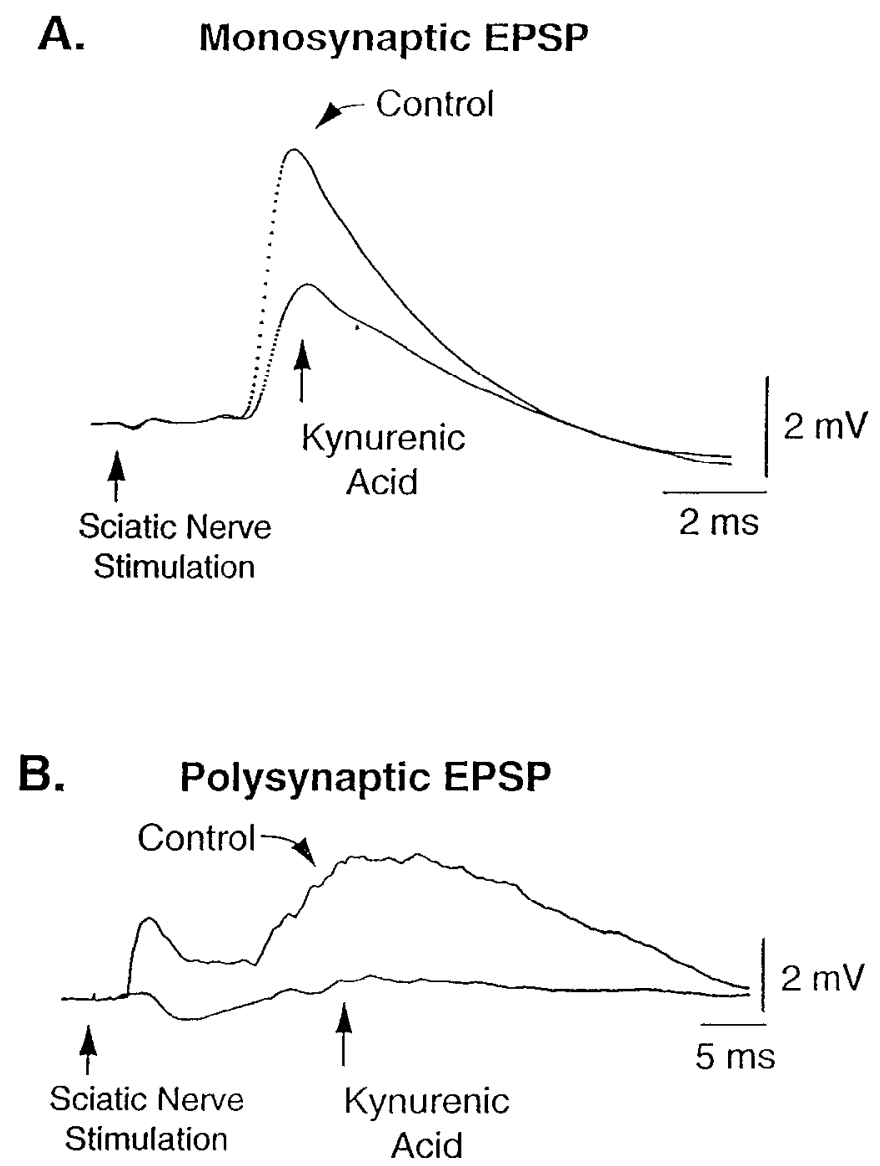

Figure 4. Membrane responses to low-intensity sciatic nerve stimulation recorded from two different motoneurons during quiet sleep before and after the juxtacellular microiontophoretic ejection of kynurenic acid. Each trace in $A$ represents the computerized average of 24 consecutive responses. The amplitude of the composite monosynaptic EPSP in $A$ was reduced by $50 \%$ following kynurenic acid ejection $(-150 \mathrm{nA}$ 2 min). Compound "early" and "late" polysynaptic EPSPs evoked by sciatic nerve stimulation before and after kynurenic acid injection $(-250 \mathrm{nA}, 5 \mathrm{~min})$ are shown in $B$. Note that kynurenic acid abolished both the "early" and "late" excitatory potentials. A small IPSP was thus unmasked. Each trace represents the average of 32 consecutive responses.

\section{Discussion}

A substantial number of studies (see reviews by Mayer and Westbrook, 1987; Collingridge and Lester, 1989; Evans, 1989) using both in vitro and in vivo preparations have indicated that kynurenic acid effectively suppresses monosynaptic transmission of primary afferent origin to several types of spinal cord neurons including motoneurons (Lambert et al., 1981; Jahr and Yoshioka, 1986; Evans, 1989), dorsal spinocerebellar tract neurons (Walmsley and Nicol, 1991), and dorsal horn interneurons (Brodin and Grillner, 1985; King et al., 1992; Zeman and Lodge, 1992). The antagonistic actions of kynurenic acid in these studies suggested that this drug interferes with NMDA, AMPA, and kainate receptor mediated synaptic transmission without inter fering with known inhibitory pathways. Employing competitive NMDA antagonists such as APV has allowed investigators to effectively distinguish between non-NMDA and NMDA mediated synaptic excitations in these studies (Brodin and Grillner, 1985; King et al., 1992; Zeman and Lodge, 1992). Thus, there are well-established bases for using kynurenic acid and APV in

\section{Motoneuron exposed to APV}

\author{
A. EOG
}

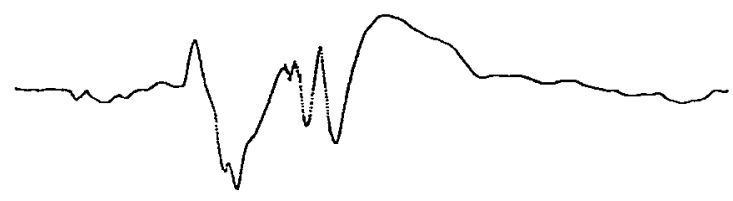

\section{B. Membrane Potential}

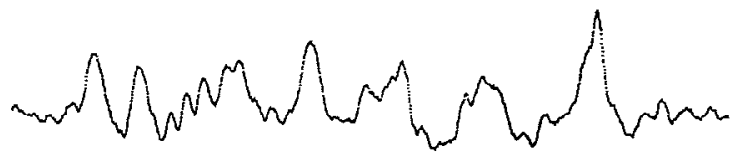

\section{$\frac{1}{0.5 \mathrm{~s}}^{\mid 2 \mathrm{mV}}$}

Figure 5. The depolarizing shifts in membrane potential that appear in lumbar nnotoneurons during REM periods of active sleep remained even following a protracted injection of APV ( $-600 \mathrm{nA}, 10 \mathrm{~min})$.

"subtractive" pharmacological experiments for investigating "fast" excitatory transmission in descending pathways to lumbar motoneurons.

In the present study we explored the issue of whether an EAA mediates the depolarizing shifts that occur in the membrane potential activity of lumbar motoneurons during the REM periods of active sleep. Microiontophoretic juxtacellular ejections of kynurenic acid blocked the REM-related phasic depolarizing potentials in lumbar motoneurons, which indicates that they are mediated by an EAA. This conclusion was supported by visual obscrvation of raw records as well as by quantitative measurements of the areas encompassed by deviations above and below the baseline membrane potential. While positive or negative values in these areas are not a direct measurement of synaptic potentials, they do provide a quantitative determination of the relative strength of hyperpolarizing and depolarizing shifts in membrane potential. For example, in motoneurons exposed to kynurenic acid, the total area measurement yielded a negative value, demonstrating a predominance of hyperpolarizing shifts, which was confirmed by visual analysis of the raw records.

To determine whether non-NMDA receptors per se or both non-NMDA and NMDA receptors mediate the depolarizing shifts in membrane potential, APV was also microiontophoretically ejected during the REM periods of active sleep. Even when APV was ejected for prolonged periods, it did not block these depolarizing shifts, suggesting that they are not mediated by NMD $\Lambda$ receptors. To confirm that $\Lambda \mathrm{PV}$ was released adequately from the electrode, two additional control experiments were performed. Microiontophoretically applied NMDA produced motoneuron depolarizations that were accompanied by an increase in input resistance, actions that were consistent with those reported previously on lumbar motoneurons in the "acute" anesthetized cat preparation (Engberg et al., 1978, 1979). In our 


\section{A NMDA Induced Depolarization}

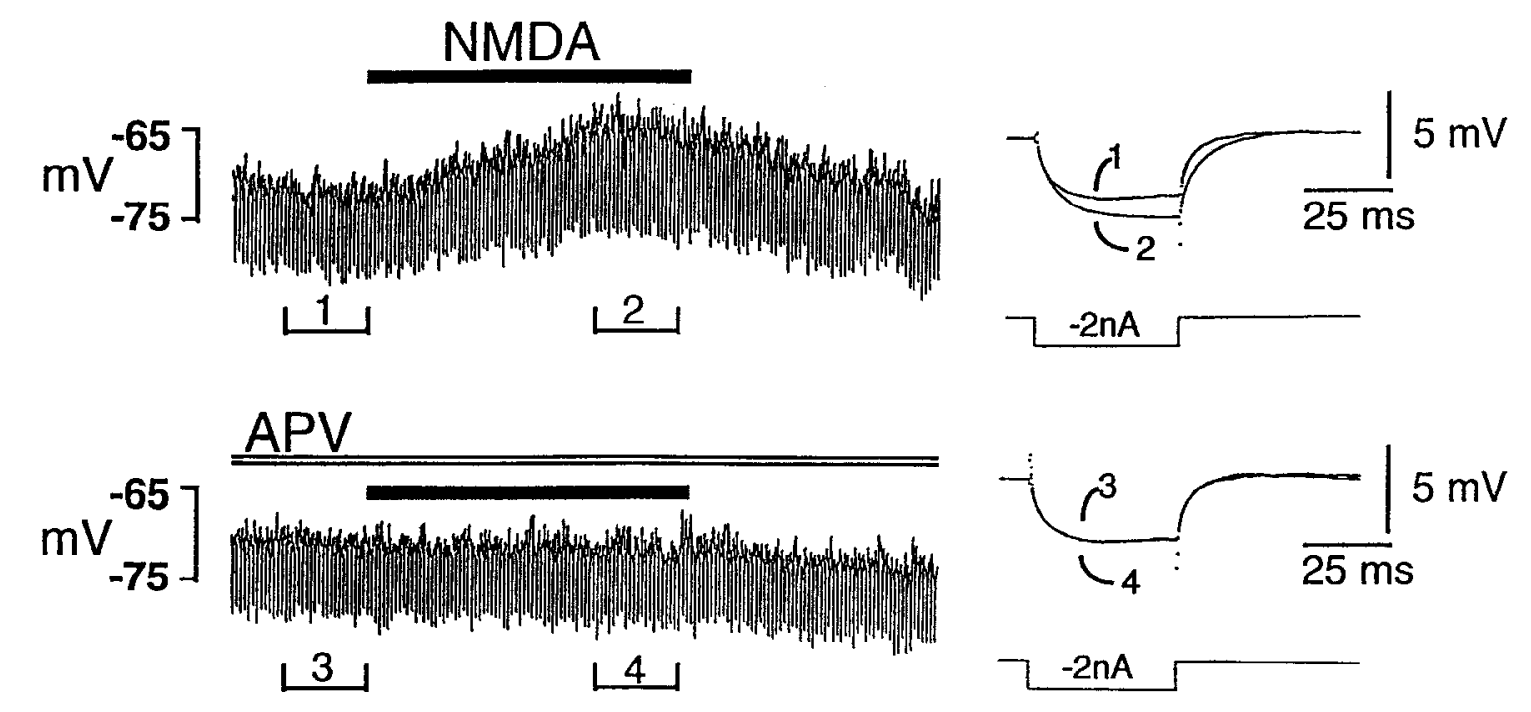

B

Composite Sciatic EPSP

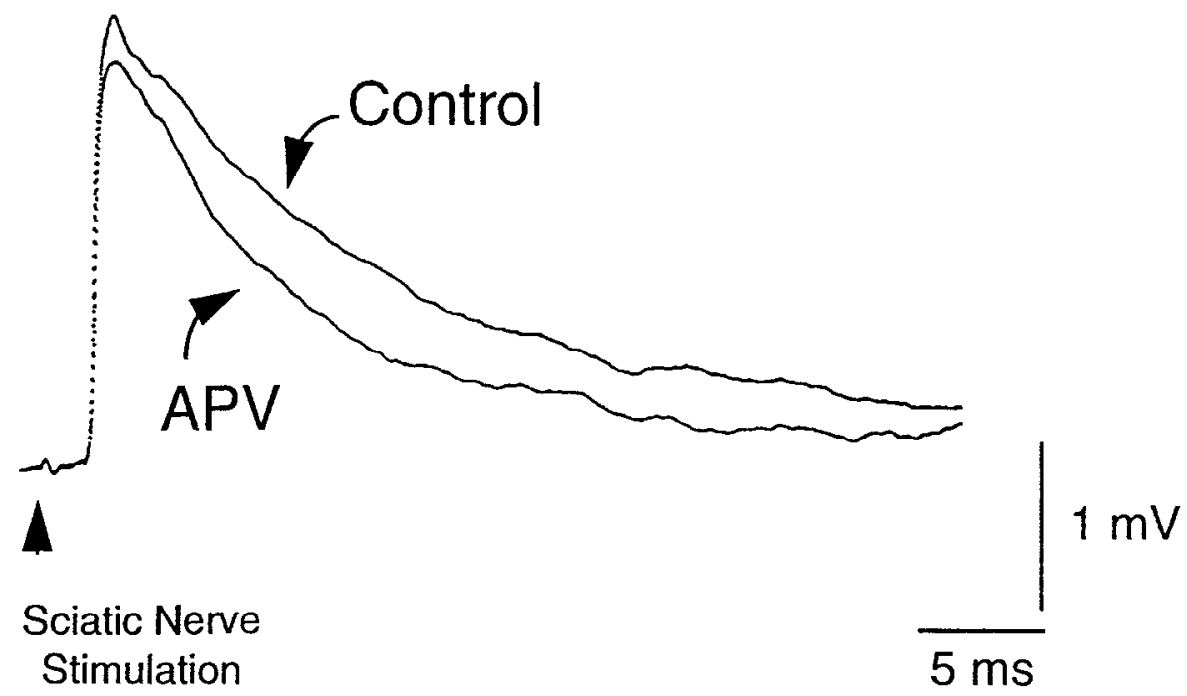

Figure 6. Effect of APV on the changes in motoneuron "resting" membrane potential produced by the microiontophoretic ejection of NMDA ( $A$ ) or polysynaptic EPSPs evoked by sciatic nerve stimulation $(B)$. Note that NMDA $(-250 \mathrm{nA}, 30 \mathrm{sec})$ depolarized the motoneuron by approximately $9 \mathrm{mV}$. NMDA failed to elicit this effect $1.5 \mathrm{~min}$ following continuous application of APV $(-300 \mathrm{nA})$. Downward deflections in $A$ represent voltage transients to the intracellular injection of hyperpolarizing current pulses $(-2 \mathrm{nA}, 50 \mathrm{msec}, 3.0 \mathrm{~Hz})$. Time-expanded averaged records of these voltage responses are illustrated to the right. Averaged voltage responses $I-4$ correspond to those demarcated by the short brackets in $A$, on the left: 1 , control; 2 NMDA; 3 , APV; 4 APV and NMDA. NMDA depolarization was accompanied by a $17.9 \%$ increase in the cell's estimated input resistance, from $4.98 \mathrm{M} \Omega$ to $6.07 \mathrm{M} \Omega$ This increase in input resistance produced by NMDA was blocked by continuous application of APV (compare voltage transient traces I vs 2 with 3 vs 4). $B$, Membrane responses to low-intensity sciatic nerve stimulation recorded from a lumbar motoneuron during quiet sleep before and after the microiontophoretic ejection of APV. Each trace represents the computerized average of 40 consecutive responses. The maximum amplitude of the composite sciatic EPSP was reduced by $10 \%$ following APV application ( -440 nA, 1.5 min). Note that the decay phase of the EPSP was markedly shortened (37\%) when compared to the control trace. (Sciatic nerve stimulation: 0.02 msec, $200 \mu \mathrm{A}, 0.5 \mathrm{~Hz})$. 
study, these actions of NMDA were blocked when APV was concurrently ejected. In addition, sciatic nerve stimulation produced composite EPSPs in lumbar motoneurons before APV application; these synaptic potentials were suppressed during the application of APV (Fig. 6B). These data demonstrate that the lack of effect of APV was not due to a failure either of the drug's release or of reaching an adequate concentration in the immcdiate vicinity of the motoneuron being recorded. Thus, we conclude that the EAA released during REM episodes of active sleep probably acts on the non-NMDA type of AMPA- or kainate-like receptors.

While there is substantial evidence confirming the involvement of NMDA receptors in mediating the polysynaptic inputs to spinal motoneurons and interneurons (Mayer and Westbrook, 1987; Collingridge and Lester, 1989; Evans, 1989), there are also reports that NMDA antagonists partially interfere with a component of monosynaptic neuronal transmission, suggesting that both non-NMDA and NMDA receptors participate in this type of synaptic activation. Further detailed studies are required to further explore the possibility that a component of certain monosynaptic excitatory inputs to motoneurons, for example, peripherally evoked EPSPS (Fig. 6B), may be sensitive to blockade by APV or other more selective potent antagonists, for example, CPP (Davies et al., 1986).

Other specific antagonists for non-NMDA receptors have also been developed, such as the quinoxalinedione derivatives CNQX, DNQX (Honoré et al., 1988), and NBQX (Sheardown et al., 1990) and the water-soluble 2,3-benzodiazepine GYKI 52466 (Tarnawa et al., 1989, 1990; Ouardouz and Durand, 1991; Donevan and Rogawski, 1993; Engberg et al., 1993; Rogawski, 1993). CNQX and DNQX were not utilized in the present work because of the well-known technical difficulty involved in the microiontophoretic ejection or these substances (see Walmsley and Bolton, 1994). However, it would be expected, according to our data, that these substances suppress, as kynurenic acid does, the phasic depolarizing shifts that occur in spinal motoneurons during REM periods of active sleep, as described in the present report. We believe that a non-NMDA AMPA-like or kainate-like EAA neurotransmitter is responsible for the REM-related depolarizing shifts in lumbar motoneurons.

In some cases the depolarizing shifts during REM periods of active sleep were not completely abolished by the microiontophoretic ejection of kynurenic acid. One likely factor that may account for this result is that receptors more distant from the sites encompassed by drug ejection may not have been exposed to a sufficient concentration of kynurenic acid. In support of the premise that there are receptors for LAAs distributed beyond the somatic region is the finding that kynurenic acid may partially hlock the monosynaptic EPSP. This suggests that the drug application was not sufficient to reach all receptors that were involved in the generation of the EPSP (Flatman et al., 1985; Walmsley and Bolton, 1994). Earlier observations by Zieglgänsberger and Champagnat (1979) that glutamate exerts preferentially more robust excitatory actions when applied to the dendritic regions of cat lumbar motoneurons as opposed to somatic regions are consistent with this notion (but see Flatman et al., 1985). We therefore suggest that a portion of the actions of EAAs during the REM periods of active sleep may be exerted at receptors located on the dendritic tree proximal to the soma and possibly at loci located farther from those affected by our microiontophoretic methods.

Although the depolarizing shifts in membrane potential were blocked by EAA antagonists, indicating a synaptic origin for these potentials, we can not discard the possible involvement of a voltage dependency in these events. For example, voltagedependent potentials that were initially described in inferior olivary neurons are produced by $\mathrm{Ca}^{2+}$ currents and are activated by transient depolarizations when the membrane potential is held at a hyperpolarized level (Llinás and Yarom, 1981a,b). These voltage-dependent phenomena have also been reported for spinal motoneurons of the neonatal rat (Harada and Takahashi, 1983; Takahashi and Berger, 1990). Consideration of the role of these voltage-dependent potentials is relevant because lumbar motoneurons are tonically hyperpolarized during active sleep (Morales and Chase, 1978); therefore, it is reasonable to postulate that large-amplitude depolarizing synaptic potentials may have activated these voltage-dependent currents. We have not determined whether there is a component of this current modality in the depolarizing shifts during the phasic REM periods of active sleep. However, even if such currents do play a role in the production of these events, the activation process must have an origin in amino acid-mediated synaptic transmission because the depolarizing shifts are blocked by kynurenic acid. Therefore, synaptic activation is a minimal requirement for the induction of REM-related depolarizing potentials in lumbar motoneurons.

Several studies have attempted to elucidate the structures and pathways that induce myoclonic activity of the limb and trunk during the REM periods of active sleep. It is likely that these structures are also involved in the generation of the excitatory postsynaptic potentials that we have described in the present study. Unitary recording studies indicate that neurons of the red nuclei, which are activated by motor cortical neurons, exert an excitatory effect on moluneurons during the REM periods of active sleep (Gassel et al., 1965). The results of the present report are consistent with this hypothesis because red nuclei neurons have been shown to utilize EAAs as neurotransmitters (Beitz and Ecklund, 1988; Benson et al., 1991). Clearly, more directed studies must be performed to establish the neuronal circuitry responsible for the REM-related depolarizing events in lumbar motoneurons during active sleep and to elucidate whether the red nuclei and/or other systems (e.g., corticospinal, reticulospinal) are involved in the production of these depolarizing events. For example, it is possible that the vestibular system may be also participate in the generation of the REM-related lumbar motoneuron depolarizing events because units recorded in the descending and medial vestibular nuclei exhibit bursts of rapid discharge during active sleep associated with episodes of REMs (Pompeiano, 1967), and lesions in the vestibular nuclei inhibit the REM periods of active sleep as well as the corresponding twitches and jerks (Morrison and Pompeiano, 1965; Morrison and Pompeiano, 1966). It is also known that the vestibular system exerts an excitatory action on motoneurons (Hongo et al., 1975).

We previously reported that excitatory and inhibitory potentials are simultaneously coactivated during the REM periods of active sleep (Chase and Morales, 1983). The inhibitory processes are blocked by strychnine (López-Rodríguez et al., 1991), indicating that glycine may be the inhibitory neurotransmitter that is released onto motoneurons, and as we have shown, the depolarizing events are blocked by kynurenic acid indicating that they may also be mediated by an EAA. Clearly, when the depolarizing events are blocked by kynurenic acid, a powerful strychnine-sensitive inhibitory process remains engaged during these periods of REMs. 
The excitatory potentials that occur in lumbar motoneurons during the REM periods of active sleep reflect an activated state whose outward manifestations are brief phasic contractions of the skeletal musculature, that is, myoclonic activity. We believe that the inhibitory potentials, which also arise during these periods, are produced by the phasic enhancement of a brainstemspinal cord inhibitory system, specific to active sleep, whose function is to compensate for the increase in phasic excitatory activity. In the present study we have shown that when the phasic inhibition is overpowered, it is by the activation of nonNMDA receptors, which results in phasic contractions of the skeletal musculature during the REM periods of active sleep.

\section{References}

Beitz AJ, Ecklund LJ (1988) Colocalization of fixative-modified glutamate and glutaminase but not GAD in rubrospinal neurons. J Comp Neurol 274:265-279.

Benson CG, Chase MC, Potashner SJ (1991) Decreased release of D-aspartate in the guinea pig spinal cord after lesions of the red nucleus. J Neurochem 56:11/4-1183.

Brodin L, Grillner S (1985) The role of putative excitatory amino acid neurotransmitters in the initiation of locomotion in the lamprey spinal cord. I. The effects of excitatory amino acid antagonists. Brain Res 360:139-148.

Chase $\mathrm{MH}$ (1970) The digastric reflex in the kitten and adult cat: paradoxical amplitude fluctuations during sleep and wakefulness. Arch Ital Biol 108:403-422.

Chase MH (1974) Somatic reflex activity during sleep and wakefulness. In: Basic sleep mechanisms (Petre-Quadens O, Schlag J, eds), pp 249-267. New York: Academic.

Chase MH, Babb M (1973) Masseteric reflex response to reticular stimulation reverses during sleep compared with wakefulness or quiet sleep. Brain Res 59:421-426.

Chase MH, Morales FR (1982) Phasic changes in motoneuron membrane potential during REM periods of active sleep. Neurosei Lett 34:177-182.

Chase MH, Morales FR (1983) Subthreshold excitatory activity and motoneuron discharge during REM periods of active sleep. Science 221:1195-1198.

Chase MH, Soja PJ, Morales FR (1989) Evidence that glycine mediates the postsynaptic potentials that inhibit lumbar motoneurons during the atonia of active sleep. J Neurosci 9:743-751.

Collingridge GL, Lester RA (1989) Excitatory amino acid receptors in the vertebrate central nervous system. Pharmacol Rev 40:143210.

Curtis DR, Phillis JW, Watkins JC (1960) The chemical excitation of spinal neurons by certain acidic amino acids. J Physiol (Lond) 150: 656-682.

Davies J, Watkins JC (1983) Role of excitatory amino acid receptors in mono and polysynaptic excitation of cat spinal cord. Exp Brain Res 49:280-290.

Davies J, Evans RH, Herrling PL, Jones AW, Olverman HJ, Pook P, Watkins JC (1986) CPP: a new potent and selective NMDA antagonist. Depression of central neuron responses, affinity for $\left[{ }^{3} \mathrm{H}\right] \mathrm{D}-$ AP5 binding sites on brain membranes and anticonvulsant activity. Brain Res 382:169-173.

Davis J, Francis AA, Jones AW, Watkins JC (1981) 2-Amino-5-phosphonovalerate (2APV), a potent and selective antagonist of amino acid-induced and synaptic excitation. Neurosci Lett 21:77-81.

Donevan SD, Rogawski MA (1993) GYKI 52466, a 2,3-benzodiazepine, is a highly selective, noncompetitive antagonist of AMPA/ kainate receptor responses. Neuron 10:51-59.

Engberg I, Flatman JA, Lambert JDC (1978) The action of $N$-methylD-aspartic and kainic acids on motoneurones with emphasis on conductance changes. Br J Pharmacol 64:384P-385P.

Engberg I, Flatman JA, Lambert JDC (1979) The actions of excitatory amino acids on motoneurons in the feline spinal cord. J Physiol (Lond) 288:227-261.

Engberg I, Tarnawa I, Durand J, Ouardouz M (1993) An analysis of synaptic transmission to motoneurones in the cat spinal cord using a new selective receptor blocker. Acta Physiol Scand 148:97-100.
Evans RH (1989) The pharmacology of segmental transmission in the spinal cord. Prog Neurobiol 33:255-279.

Fagg GE, Foster AC (1983) Amino acid neurotransmitters and their pathways in the mammalian central nervous system. Neuroscience 9:701-719.

Flatman JA, Lambert JD, Engberg I (1985) The variation in action of cxcitatory amino acids in relation to distance of iontophoretic application to spinal motoneurones. Acta Physiol Scand 124:421 427.

Ganong AH, Lanthorn TH, Cotman CW (1983) Kynurenic acid inhibits synaptic and amino acid induced responses in the rat hippocampus and spinal cord. Brain Res 273:170-174.

Gassel MM, Marchiafava PL, Pompeiano O (1964a) Phasic changes in muscular activity during desynchronized sleep in unrestrained cats. An analysis of the patterns and organization of myoclonic twitches. Arch Ital Biol 102:449-470.

Gassel MM, Marchiafava PL, Pompeiano O (1964b) Tonic and phasic inhibition of spinal reflexes during sleep, desynchronized sleep in unrestrained cats. Arch Ital Biol 102:471-499.

Gassel MM, Marchiafava PL, Pompeiano O (1965) Activity of the red nucleus during deep desynchronized sleep in unrestrained cats. Arch Ital Biol 103:369-396.

Graham LT, Shank RP, Werman R, Aprison MH (1967) Distribution of some synaptic transmitter suspects in act spinal cord: glutamic acid, aspartic acid, $\gamma$-aminobutyric acid, glycine, and glutamine. $\mathbf{J}$ Neurochem 14:465-472.

Harada Y, Takahashi T (1983) The calcium component of the action potential in spinal motoneurons of the rat. $\mathbf{J}$ Physiol (Lond) 335: $89-100$.

Headley PM, Grillner S (1990) Excitatory amino acids and synaptic transmission: the evidence for a physiological function. Trends Pharmacol Sci 11:205-211.

Hendricks JC, Morrison AR, Mann GL (1982) Different behaviors during paradoxical sleep without atonia depend on pontine lesions site. Brain Res 239:81-105

Hongo T, Kudo N, Tanaka R (1975) The vestibulospinal tract: crossed and uncrossed effects on hindlimb motoneurons in the cat. Exp Brain Res 24:37-55.

Honoré T, Davies SN, Drejer J, Fletcher EJ, Jacobsen P, Lodge D, Nielsen FF (1988) Quinoxalinediones: potent competitive nonNMDA glutamate receptor antagonist. Science 241:701-703.

Jahr CE, Yoshioka K (1986) Ia afferent excitation of motoneurones in the in vitro new-born rat spinal cord is selectively antagonized by kynurenate. J Physiol (Lond) 370:515-530.

Johnson JL, Aprison MH (1971) The distribution of glutamate and total free amino acids in thirteen specific regions of the cat central nervous system. Brain Res 26:141-148.

Jouvet M, Michel F, Courjon J (1959) L'activité électrique du rhinencéphale au cours du commeil chez le chat. CR Soc Biol 153: $101-105$.

King AE, Lopez-Garcia JA, Cumberbatch M (1992) Antagonism of synaptic potentials in ventral horn neurones by 6-cyano-7-nitroquinoxaline-2,3-dione: a study in the rat spinal cord in vitro. $\mathrm{Br} \mathbf{J}$ Pharmacol 107:375-381.

Lambert JD, Flatman JA, Engberg I (1981) Actions of excitatory amino acids on membrane conductances and potential in motoneurones. Adv Psychopharmacol 27:205-216.

Llinás R, Yarom Y (1981a) Electrophysiology of mammalian inferior olivary neurons in vitro. J Physiol (Lond) 315:549-567.

Llinás R, Yarom Y (1981b) Properties and distribution of ionic conductances generating electroresponsiveness of mammalian inferior olivary neurons in vitro. J Physiol (Lond) 315:569-584.

López-Rodríguez F, Morales FR, Soja PJ, Chase MH (1991) Suppression of PGO-related motoneuron IPSPs by strychnine. Brain Res 535:331-334.

Mayer ML, Westbrook GL (1987) The physiology of excitatory amino acids in the vertebrate central nervous system. Prog Neurobiol 28:197-276.

Monaghan DT, Bridges RJ, Cotman CW (1989) The excitatory amino acid receptors their classes, pharmacology, and distinct properties in the function of the central nervous system. Annu Rev Pharmacol Toxicol 2:365-402.

Morales FR, Chase MH (1978) Intracellular recording of lumbar motoneuron membrane potential during sleep and wakefulness. Exp Neurol 62:821-827. 
Morales FR, Chase MH (1982) Repetitive synaptic potentials responsible for inhibition of spinal cord motoneurons during active sleep. Exp Neurol 78:471-476.

Morales FR, Schadt J, Chase MH (1981) Intracellular recording from spinal cord motoneurons in the chronic cat. Physiol Behav 27:355362 .

Morales FR, Boxer PA, Chase MH (1985) Behavioral state specific inhibitory postsynaptic potentials impinge on cat lumbar motoneurons during active sleep. Exp Neurol 98:418-435.

Morrison AR, Pompeiano O (1965) Pyramidal discharge from somato-sensory cortex and cortical control of primary afferents during sleep. Arch Ital Biol 103:538-568.

Morrison AR, Pompeiano O (1966) Vestibular influences during sleep. II. Effects of vestibular lesions on the pyramidal discharge during desynchronized sleep. Arch Ital Biol 104:214-230.

Ouardouz M, Durand J (1991) GYKI 52466 antagonizes glutamate responses but not NMDA and kainate responses in rat abducens motoneurones. Neurosci Lett 125:5-8.

Perkins MN, Stone TW (1982) An iontophoretic investigation of the actions of convulsant kynurenines and their interaction with the endogenous excitant quinolinic acid. Brain Res 247:184-187

Perkins MN, Stone TW, Collins JF, Curry K (1981) Phosphonate analogues of carboxylic acids as amino acid antagonists on rat cortical ncurons. Neurosci Lett 23:333-336.

Pompeiano O (1967) The neurophysiological mechanisms of the postural and motor events during desynchronized sleep. Proc Assoc Res Nerv Dis 45:351-423.

Pompeiano $O$ (1978) The generation of rhythmic discharges during burst of REM. In: Abnormal neuronal discharges (Chalazonitis $\mathrm{N}$, Boisson M, eds), pp 75-89. New York: Raven.

Puil E (1981) S-glutamate: its interactions with spinal neurons. Brain Res Rev 228:229-322.

Rizzoli AA (1968) Distribution of glutamic acid, aspartic acid, $\gamma$-aminobutyric acid and glycine in six areas of cat spinal cord before and after transection. Brain Res 11:11-18.

Rogawski MA (1993) Therapeutic potential of excitatory amino acid antagonists: channel blockers and 2,3 benzodiazepines. Trends Pharmacol Sci 14:325-331.
Sheardown MJ, Nielsen EO, Hansen AJ, Honoré T (1990) 2,3-Dihydro-6-nitro-7-sulfamoyl-benzo(F)quinoxaline: a neuroprotectant for cerebral ischemia. Science 247:571-574.

Soja PJ, Morales FR, Baranyi A, Chase MH (1987) Effect of inhibitory amino acid antagonists on the IPSPs induced in lumbar motoneurons upon stimulation of the nucleus reticularis gigantocellularis during active sleep. Brain Res 423:353-358.

Soja PJ, López F, Morales FR, Chase MH (1991) The postsynaptic inhibitory control of lumbar motoneurons during quiet sleep and active sleep: effect of strychnine on motoneuron properties. J Neurosci 11:2804-2811.

Takahashi T, Berger AJ (1990) Direct excitation of rat spinal cord motoneurones by serolonin. J Physiol (Lond) 423:63-76.

Tarnawa I, Farkas S, Berzsenyi P, Pataki A, Andrasi F (1989) Electrophysiological studies with a 2,3-benzodiazepine muscle relaxant: GYKI 52466. Eur J Pharmacol 167:193-194.

Tarnawa I, Engberg I, Flatman JA (1990) GYKI 52466, an inhibitor of spinal reflexes is a potent quisqualate antagonist. In: Amino acids: chemistry, biology and medicine (Lubec G, Rosenthal GA, eds), pp 538-546. Ledien, Netherlands: Escom.

Lrsin R, Sterman MB (1981) A manual for standardized scoring of sleep and waking states in the adult cat, pp 1-103. Los Angeles: Brain Information Service, Brain Research Institute UCLA.

Walmsley B, Bolton PS (1994) An in vivo pharmacological study of single group Ia fibre contacts with motoneurones in the cat spinal cord. J Physiol (Lond) 481:731-741.

Walmsley B, Nicol MJ (1991) The effects of $\mathrm{Ca}^{2+}, \mathrm{Mg}^{2+}$ and kynurenate on primary afferent synaptic potentials evoked in cat spinal cord neurones in vivo. J Physiol (Lond) 433:409-420.

Young AB, Penney JB, Dauth GW, Bromberg MB, Gilman S (1983) Glutamate or aspartate as a possible neurotransmitter of cerebral cortifugal fibers in the monkey. Neurology 33:1513-1516.

Zeman S, Lodge D (1992) Pharmacological characterization of nonNMDA subtypes of glutamate receptor in the neonatal rat hemisected spinal cord in vitro. Br J Pharmacol 106:367-372.

Zieglgänsberger W, Champagnat J (1979) Cat spinal motoneurones exhibit topographic sensitivity to glutamate and glycine. Brain Res $160: 95 \cdots 104$. 